\title{
RETAINED AUSTENITE THERMAL STABILITY IN A NANOSTRUCTURED
}

\section{BAINITIC STEEL}

\author{
Behzad Avishan $^{* a}$, Carlos Garcia-Mateo ${ }^{\mathrm{b}}$, Sasan Yazdani ${ }^{\mathrm{a}}$, Francisca G. Caballero ${ }^{\mathrm{b}}$
}

${ }^{a}$ Faculty of Materials Engineering, Sahand University of Technology, Tabriz, Iran.

b Department of Physical Metallurgy, National Centre for Metallurgical Research (CENIM-CSIC), MATERALIA Research Group. Avda. Gregorio del Amo, 8, 28040, Madrid, Spain.

*a) b_avishan@sut.ac.ir , Tel.: +98 412 3459460; fax: +98 4123444333.

b) cgm@cenim.csic.es

c) yazdani@sut.ac.ir

d) fgc@cenim.csic.es

\begin{abstract}
The unique microstructure of nanostructured bainite consists of very slender bainitic ferrite plates and high carbon retained austenite films. As a consequence, the reported properties are opening a wide range of different commercial uses. However, bainitic transformation follows the $T_{0}$ criteria, i. e. the incomplete reaction phenomena, which means that the microstructure is not thermodynamically stable because the bainitic transformation stops well before austenite reaches an equilibrium carbon level. This article aims to study the different microstructural changes taking place when nanostructured bainite is destabilized by austempering for times well in excess of that strictly necessary to end the transformation. Results indicate that while bainitic ferrite seems unaware of the extended heat treatment, retained austenite exhibits a more receptive behavior to it.
\end{abstract}

\section{Keywords}

Nanostructured bainite; thermal stability; scanning electron microscopy; transmission electron microscopy; X-ray diffraction. 


\section{Introduction}

Nowadays bainite in form of long slender crystals of ferrite scale of which compares with that of carbon nanotubes [1], has a very good chance of proper commercialization [2, 3]. This so called nanostructured bainite, in which extremely fine 20-40nm thick platelets of bainitic ferrites are dispersed in a matrix consisting of carbon enriched retained austenite [1, 4-7], has reported to have a very promising combination of mechanical properties [8-10] never reported for bainitic microstructures before. The microstructure is not thermodynamically stable because the reaction stops when austenite reaches a carbon level defined by the $T_{0}$ curve of the phase diagram, rather than when the equilibrium is achieved given by Ae3 curve [11-13]. The transformation mechanism leads to a ferrite carbon concentration, which is many orders of magnitude greater than its equilibrium solubility [7, 12, 14-16]. However, the microstructure is carbide free, not only because Si retards the precipitation of cementite from austenite due to its low-solid solubility in the cementite crystal structure, but also, as it has been recently probed by atom-probe tomography $[12,17]$, because a substantial quantity of carbon is trapped at accommodation twins and dislocations in vicinity of the ferrite-austenite interface (Cottrell atmospheres) which prevents decarburization of super-saturated bainitic ferrite and therefore alters the carbide precipitation sequence during low-temperature bainite formation and even during its tempering processes $[16,18,19]$.

Tempering usually implies temperatures lower than Ac1, but higher than the bainite start temperature, Bs. In this sense, Bhadeshia and coworkers [20-24], all have investigated the microstructural changes of different carbide free bainitic steels at tempering temperatures ranging 400 to $750^{\circ} \mathrm{C}$, well above the Bs temperature. In general the sequence is, carbide precipitation at early stages followed by austenite decomposition and final ferrite coarsening. In a similar context, microstructural changes can also occur when austenite is transformed isothermally to bainite, and then held at the transformation temperatures for times longer than is necessary to end the bainite reaction [11]. Giving the low transformation temperatures at which nanostructured bainite forms, the time needed to finish 
transformation might be extended to several days [4, 25]. Therefore it is not strange that the effect of extended heat treatment in these microstructures has not been reported widely in the literature.

The goal of this work is to analyze the effect that bainitic heat treatment at $200^{\circ} \mathrm{C}$, has on the microstructure of a variant of nanostructured bainitic steels after austempering for times more than that strictly needed to complete the transformation.

\section{Material and methods}

Primary ingot with chemical composition of Fe- 0.91C- $1.58 \mathrm{Si}-1.98 \mathrm{Mn}-0.06 \mathrm{Ni}-0.25 \mathrm{Mo}-1.12 \mathrm{Cr}-$ 1.37Co- $0.53 \mathrm{Al}$ was cast in an induction furnace under inert atmosphere. The alloy contains Mn and Cr to provide with enough hardenability so no other transformations takes place before bainitic reaction. Si addition is made to prevent cementite precipitation during bainitic transformation and Mo is added to prevent temper embrittlement due to $\mathrm{P}$ [26]. The $\mathrm{C}$ concentration was selected to suppress $\mathrm{B}_{\mathrm{S}}$ and $\mathrm{M}_{\mathrm{S}}$, and $\mathrm{Co}$ and $\mathrm{Al}$ were added in order to accelerate the transformation kinetics, as both elements increase the driving force for transformation of austenite into ferrite of the same composition [25]. The cast was electro slag remelted and then homogenized at $1200^{\circ} \mathrm{C}$ for $2 \mathrm{~h}$, and then hot rolled at a temperature of about $950^{\circ} \mathrm{C}$. Finally lumps of $5 \times 5 \times 10 \mathrm{~mm}^{3}$ were cut and prepared for heat treatments. Austenitization was performed at $900^{\circ} \mathrm{C}$ for $30 \mathrm{~min}$, the Ac3 was determined by high resolution dilatometry to be $845^{\circ} \mathrm{C}$. Immediately after, samples were transferred to a salt bath at $200^{\circ} \mathrm{C}$, a temperature well above the experimentally determined $\mathrm{Ms}=114^{\circ} \mathrm{C}$. A set of samples were hold isothermally at $200^{\circ} \mathrm{C}$ for $74 \mathrm{~h}$, time needed to complete bainitic transformation. Another set was kept for 92h in order to study the possible effect of extended austempering. In both cases, once the heat treatment was over, samples were quenched into water.

To reveal the microstructure, metallographic samples were cut, ground and polished following the standard procedures and samples were polished using colloidal silica suspension before etching. A 2\% Nital etching solution was used to reveal bainitic microstructure. Scanning electron microscopy observation was carried out on a FEG-SEM HITACHI S-4800 field emission gun scanning electron 
microscope, operating at 7kV. High magnification SEM-FEG micrographs were used to determine the distribution and size of austenite films and also the bainitic ferrite plate thickness, $t$, by measuring the mean lineal intercept $\bar{L}_{T}=\pi t / 2$ in a direction normal to the plate length [25, 27].

TEM specimens were punched to 3-mm-diameter disks of heat-treated material, mechanically thinned to $0.06 \mathrm{~mm}$ and then twin-jet electropolished to perforation using a mixture of 5\% perchloric acid, $25 \%$ glycerol and $70 \%$ ethanol at $-6{ }^{\circ} \mathrm{C}$ at $45 \mathrm{~V}$. Samples were studied on a TEM JEOL 2100 transmission electron microscope operating at $200 \mathrm{kV}$.

Quantitative X-ray diffraction analysis was used to determine the volume fraction of retained austenite $\left(\mathrm{V}_{\gamma}\right)$ and its carbon content $\left(\mathrm{C}_{\gamma}\right)$. For this purpose, samples were machined, ground and finally polished using $1 \mu \mathrm{m}$ diamond paste, and then were subjected to several cycles of etching and polishing to obtain an undeformed surface, a final polish with colloidal silica was then applied. X-ray diffraction measurements were performed with a Bruker AXS D8 diffractometer equipped with X-ray Co tube and Goebel mirror optics to obtain a parallel and monochromatic X-ray beam. A current of 30mA and a voltage of $40 \mathrm{kV}$ were used. Operational conditions were selected to obtain X-ray diffraction diagrams of sufficient quality: sufficient counting statistics and narrow peaks. XRD data were collected over a $2 \theta$ range of $30-115^{\circ}$ with a step width of $0.03^{\circ}$ and a counting time of 4 sec/step.

The volume fraction of retained austenite and bainitic ferrite was calculated from the integrated intensities of (111), (200), (220) and (311) austenite peaks, and those of (110), (200) and (211) peaks of ferrite. Using this number of peaks avoids possible bias due to crystallographic texture [28]. For each diffraction pattern, the austenite lattice parameter was determined applying the Cohen's method [29, 30]. The parameters calculated from individual peaks were plotted against $\cos ^{2}\{\theta\} / \sin \{\theta\}$, and the precise lattice parameters were obtained by extrapolating the diffraction angle $\theta$ to $90^{\circ}$, with the highest angles being given the greatest weights in the extrapolation. The weighting was carried out by conducting regression analysis on a data set containing just one point for the lowest $\theta$ value, two 
identical points for the next $\theta$ value and so on. This is because the largest $2 \theta$ are associated with smaller errors in the calculation of lattice parameters.

Austenite carbon content was estimated using well-known Dyson and Holmes' equation that relates the austenite lattice parameter to its composition [31]. Although this expression has been validated in several works $[9,24,25]$, additional considerations should be performed to take into account the effects of substitutional elements. In bainitic transformation nucleation takes place under paraequilibrium conditions, meaning that only carbon diffuses and growth happens without change in the chemical composition i.e. diffusionless $[11,12,14,15]$. Therefore those conditions are taken into account when calculating the austenite $\mathrm{C}$ content as: $\left(\mathrm{x}_{\mathrm{Fe}} / \mathrm{x}_{\mathrm{j}}\right)_{\text {bulk }}=\left(\mathrm{x}_{\mathrm{Fe}} / \mathrm{x}_{\mathrm{j}}\right)_{\gamma}$, where $\mathrm{j}$ denotes any substitutional element in the alloy, and $\mathrm{x}_{\mathrm{Fe}}$ and $\mathrm{x}_{\mathrm{j}}$ are the concentrations of $\mathrm{Fe}$ and substitutional elements respectively. If this condition is introduced in Dyson and Holmes' equation in conjunction with the fact that $\sum\left(\mathrm{x}_{\mathrm{i}}\right)_{\gamma}=100$, i denotes all elements in the chemical composition, it gives rise to a system where the austenite $\mathrm{C}$ content is accurately calculated by an iteration process.

The X-ray data from the microstructure were also analyzed for non-uniform strains. Diffraction peaks are broadened by both, the presence of non-uniform strains that systematically shift atoms from their ideal positions, and by the finite crystallite size (coherently diffracting domain). These two effects have a different dependence on the value of $\theta$, which is the Bragg angle [32]. The non-uniform strain effect can therefore be separated, since the slope of a plot of $\beta_{\mathrm{hkl}} \cos \left\{\theta_{\mathrm{hkl}}\right\}$ versus $\sin \left\{\theta_{\mathrm{hkl}}\right\}$ is equal to the strain $\varepsilon$ [32]. The parameter $\beta$ is the measured peak broadening; it is defined as the width of a rectangle with the same area and height as the diffraction peak. In general, $\varepsilon$ is proportional to the square root of the dislocation density [33].

Finally hardness was measured as $\mathrm{HV}_{30}$ and the presented results correspond to an average of at least 3 values.

\section{Results and discussion}


As expected from the high $\mathrm{C}$ content of steel and the additional $\mathrm{C}$ enrichment at which austenite is subjected during bainitic transformation, martensitic transformation was suppressed during cooling down to room temperature. Thus the microstructure consists essentially of a mixture of two phases, bainitic ferrite and carbon enriched regions of retained austenite. Fig. 1 (a) to (d) illustrate the microstructure at different magnifications for both specimens, treated for $74 \mathrm{~h}$ and $92 \mathrm{~h}$. At lower magnification, Fig. 1 (a) and (b), it is possible to observe micro-blocks of retained austenite (darker features) trapped between sheaves of bainite (lighter and feather like features). Sheaf is a term which refers to groups of bainitic ferrite plates sharing a common crystallographic orientation and interwoven with thin films of retained austenite, only visible at higher magnifications, like in Fig. 1 (c) to (f), where the lighter phase is retained austenite and the darker with a lower profile is bainitic ferrite. In both cases, 74h and 92h, bainitic ferrite is the majority phase with a fraction of $0.60 \pm 0.03$. Fig. 1 (e) and (f) also reveal the real scale of the microstructure, within the nano range, as it is also supported by plate thickness measurements in Fig. 2, i. e. 39 and $38 \mathrm{~nm}$ for $74 \mathrm{~h}$ and $92 \mathrm{~h}$ respectively. The refinement of the microstructure is not exclusive of the bainitic ferrite and retained austenite films trapped between the slender plates of ferrite, like those shown in Fig. (c) to (f), have an average size of 38 and $34 \mathrm{~nm}$ for $74 \mathrm{~h}$ and $92 \mathrm{~h}$ heat treatments. The only apparent difference between both treatments is the slight decrease in the retained austenite film thickness as the treatment time is increased.

$\mathrm{X}$ ray analysis revealed that, within the limits of experimental determination, ferrite lattice parameter in both microstructures is almost identical, $\sim 2.871 \AA$, see Fig. 3. But for austenite there are some differences, even appreciable as $2 \theta$ displacements of the $\gamma$ peaks in Fig. 3, leaving a lattice parameter of $3.617 \AA$ and $3.611 \AA$ for $74 \mathrm{~h}$ and $92 \mathrm{~h}$ treatments respectively. In other words the measured C content in austenite changes from $\mathrm{C}_{\gamma}=1.01 \pm 0.05$ wt. $\%$ to $\mathrm{C}_{\gamma}=0.84 \pm 0.05$ wt. $\%$ respectively.

Giving its displacive nature, the transformation of bainite causes a deformation that is plastically relaxed by austenite, therefore the process implies the formation of dislocations in both, austenite and bainitic ferrite [11, 17, 34, 35]. As detailed, an indirect measurement of the dislocation density results 
from the microstrain measurement. Based on the broadening of X-ray diffraction peaks, the microstrain value obtained for bainitic ferrite, $\approx 6.2 \pm 0.2 \times 10^{-3}$, does not vary from one heat treatment to another and calculated dislocation density is $1.1 \times 10^{16} \mathrm{~m}^{-2}$. In the case of retained austenite the measured microstrain differences resulted in dislocation densities of $6.9 \times 10^{15}$ and $6.4 \times 10^{15} \mathrm{~m}^{-2}$ for the 74h and the 92h treatments respectively. This implies that the dislocation density does not change in the bainitic ferrite from one microstructure to another. However, longer treatment time leads to a small reduction of dislocation density in austenite. It has to be noted that reported dislocation density values are in good agreement with those previously published for similar microstructures [8, 34].

The very high HV values of $530 \pm 10$ and $610 \pm 10$ for the $74 \mathrm{~h}$ and $92 \mathrm{~h}$ treatments, respectively are a direct consequence of the nanoscale and the fraction of bainitic ferrite, considered as the hard phase when compared with austenite. Since bainitic ferrite is almost identical in both treatments (fraction, thickness and microstrain), the difference in $\mathrm{HV}$ has to be related, directly or indirectly, to $\mathrm{C} \gamma$ variations and to a lesser extent to the small difference in dislocation density in austenite. A priori the higher the $\mathrm{C}$ in solid solution and the higher dislocation density are, the stronger the phase is expected to be, which seems to be in contradiction with the increase in HV detected as the treatment time is extended from that needed to complete bainitic transformation.

A more detailed observation of the microstructure using TEM, Fig. 4, emphasizes the scale of the microstructure and the intense dislocation debris, occurring as a consequence of the displacive growth of bainite, and very evident in Fig. 4 (c), where extensive dislocation debris is evident in a film of retained austenite. But the inspection of the microstructure by TEM brings up the presence of small precipitates in the microstructure obtained after $92 \mathrm{~h}$ at $200^{\circ} \mathrm{C}$. By chemical analysis, EDX and indexing of their corresponding diffraction patterns, see Fig. 5, the precipitates were conclusively identified to be cementite with lattice parameters of $\mathrm{a}=4.0995 \AA, \mathrm{b}=4.4700 \AA$ and $\mathrm{c}=6.4639 \AA$ which are similar to those reported in the literature, see for example [11]. As expected, TEM observation failed to reveal any epsilon carbide within the microstructure, as this transitional carbide has been only 
observed by Atom Probe Tomography (APT) at tempering temperature between $400-450^{\circ} \mathrm{C}$ in this type of microstructures [16, 36].

So it seems evident that holding at transformation temperatures for times longer than is necessary to complete the bainite reaction, leads to a local reduction in austenite carbon concentration following the precipitation of cementite in this phase. At that stage of the studied microstructure, ferrite is completely unaware of the extended time, while the carbon enriched austenite slowly attempts to reach the equilibrium by rejecting the excess $\mathrm{C}$ as cementite precipitates without reducing its volume fraction [21].

As an important outcome in this particular case, long exposure to heat treatment temperature did not lead to the typical tempering sequence of bainitic microstructure [11, 24], where redistribution of C from supersaturated bainitic ferrite into austenite is expected to be followed by precipitation of carbides in bainitic ferrite and finally decomposition of austenite into a mixture of cementite and ferrite. We speculate that, as reported for this low temperature bainitic microstructures [12, 17], the intense dislocation density and the presence of nano-twins, both capable of trapping $\mathrm{C}$, are playing an important role in the tempering sequence. This is object of ongoing research.

It has to be noted that, the decrease in $\mathrm{C}$ content of austenite by cementite precipitation does not impoverish it sufficiently to increase its Ms to room temperature. Therefore austenite remains stable during cooling to ambient temperature after the heat treatment, as confirmed by X-ray results. Therefore the detected increase in $\mathrm{HV}$ was not a consequence of the presence of martensite as it has been reported before in [21, 37], but most likely due to the presence of hard precipitates of cementite. The term secondary hardening is generally associated with heavily alloyed steels where the presence of strong carbide former elements ( $\mathrm{Mo}, \mathrm{Cr}, \mathrm{W}$ and $\mathrm{V}$ ) is required to enhance fine secondary precipitation during tempering at temperatures ranging from 450 up to $600^{\circ} \mathrm{C}$ [38-40], where formation of alloy carbides necessitates the long range diffusion of substitutional atoms, in principle, which seems very unlikely at $200^{\circ} \mathrm{C}$. Given the chemical composition and the transformation 
temperatures used in this work, it seems safe to conclude that secondary hardening is not playing a role in the detected increase in hardness.

Finally it is difficult to anticipate the effect that the presence of these cementite particles might have on the final mechanical properties. In the case of toughness, fraction, size and distribution of cementite would have a determining role, while the associated decrease in C content in austenite and its dislocation density might assist ductility. In terms of the strength, it is not expected a relevant difference, as extremely fine bainitic plate thickness, $t$, is the main contribution to this property [8, 41], and, as it has been reported in this study, the fraction and size of bainitic ferrite are almost identical in both heat treatments.

\section{Summary}

The prolonged austempering behavior of a mixture of nanostructured bainitic ferrite and carbon enriched retained austenite has been studied using X-ray and electron microscopy. The heat treatment consisted of isothermal transformation at $200^{\circ} \mathrm{C}$ for times longer $(92 \mathrm{~h})$ than that strictly necessary to complete bainitic transformation i.e. 74h. A novel picture has emerged for this condition and it appears that the extensive austempering implies the precipitation of minutes quantities of cementite from supersaturated austenite. The process does not make the austenite sufficiently unstable for martensitic transformation on cooling, while bainitic ferrite remains unaware of the process.

\section{Acknowledgements}

Authors are acknowledging the National Center for Metallurgical Researches (CENIM-CSIC) and Sahand University of Technology for providing the research facilities. The authors acknowledge E. URONES-GARROTE from the Centro de Microscopia and Citometria (UCM) for the assistance with the TEM. C. Garcia-Mateo and F.G. Caballero would like to thank Spanish Ministerio de Economia y Competitividad Plan Nacional de I+D+I (2008-2011) for supporting their research under the project MAT2010-15330. 


\section{References}

[1] F.G. Caballero, H.K.D.H. Bhadeshia, Current Opinion in Solid State and Materials Science, 8 (2004) 251-257.

[2] H.K.D.H. Bhadeshia, P. Brown, C. Garcia-Mateo, Bainite steel and methods of manufacture thereof, patent no. GB2462197, 2010.

[3] F.G. Caballero, H. Bhadeshia, K.J.A. Mawella, D.G. Jones, P. Brown, Materials Science and Technology, 18 (2002) 279-284.

[4] C. García Mateo, F.G. Caballero, H.K.D.H. Bhadeshia, ISIJ International, 43 (2003) 1238-1243.

[5] H.K.D.H. Bhadeshia, Materials Science and Technology, 21 (2005) 1293-1302.

[6] P.M. Brown, D.P. Baxter, Materials Science and Technology, (2004) 433-438.

[7] C. Garcia-Mateo, F.G. Caballero, M.K. Miller, J.A. Jimenez, Journal of materials science, 47 (2012) 1004-1010.

[8] C. Garcia-Mateo, F.G. Caballero, ISIJ international, 45 (2005) 1736-1740.

[9] C. García Mateo, F.G. Caballero, Materials Transactions, 46 (2005) 1839-1846.

[10] C. Garcia-Mateo, F.G. Caballero, T. Sourmail, M. Kuntz, J. Cornide, V. Smanio, R. Elvira, Materials Science and Engineering: A, 549 (2012) 185-192.

[11] H.K.D.H. Bhadeshia, Bainite in Steels, $2^{\text {nd }}$ ed., Institute of Materials, London, 2001.

[12] F.G. Caballero, M.K. Miller, S.S. Babu, C. García-Mateo, Acta materialia, 55 (2007) 381-390.

[13] B. Avishan, S. Yazdani, S.H. Nedjad, Materials Science and Engineering: A, (2012).

[14] H.K.D.H. Bhadeshia, A.R. Waugh, Acta Metallurgica, 30 (1982) 775-784.

[15] F.G. Caballero, M.K. Miller, C. Garcia-Mateo, Materials Science and Technology, 26 (2010) 889-898.

[16] F.G. Caballero, M.K. Miller, A.J. Clarke, C. Garcia-Mateo, Scripta Materialia, 63 (2010) 442445.

[17] F.G. Caballero, H.W. Yen, M.K. Miller, J.R. Yang, J. Cornide, C. Garcia-Mateo, Acta materialia, 59 (2011) 6117-6123.

[18] F.G. Caballero, M.K. Miller, C. Garcia-Mateo, C. Capdevila, S.S. Babu, Acta materialia, 56 (2008) 188-199.

[19] F.G. Caballero, M.K. Miller, C. Garcia-Mateo, Journal of materials science, 43 (2008) 37693774.

[20] H.K.D.H. Bhadeshia, D.V. Edmonds, Metallurgical and Materials Transactions A, 10 (1979) 895907.

[21] A. Saha Podder, H.K.D.H. Bhadeshia, Materials Science and Engineering: A, 527 (2010) 21212128.

[22] F.G. Caballero, H.K.D.H. Bhadeshia, K.J.A. Mawella, D.G. Jones, P. Brown, Materials Science and Technology, 17 (2001) 517-522.

[23] H.S. Hasan, M.J. Peet, H.K.D.H. Bhadeshia, International journal of materials research, 103 (2012) 1319-1324.

[24] C. Garcia-Mateo, M. Peet, F.G. Caballero, H.K.D.H. Bhadeshia, Materials Science and Technology, 20 (2004) 814-818.

[25] C. García Mateo, F.G. Caballero, H.K.D.H. Bhadeshia, ISIJ International, 43 (2003) 1821-1825.

[26] S.H. Song, R.G. Faulkner, P.E.J. Flewitt, Materials Science and Engineering: A, 281 (2000) 2327.

[27] L.C. Chang, H.K.D.H. Bhadeshia, Materials Science and Technology, 11 (1995) 874-881.

[28] M.J. Dickson, Journal of applied Crystallography, 2 (1969) 176-180.

[29] B.D. Cullity, S.R. Stock, Elements of X- Ray diffraction, $3^{\text {rd }}$ ed., Prentice Hall, New York, 2001.

[30] H.W. King, E.A. Payzant, Canadian metallurgical quarterly, 40 (2001) 385-394.

[31] D.J. Dyson, B. Holmes, J Iron Steel Inst, 208 (1970) 469-474.

[32] G.K. Williamson, W.H. Hall, Acta Metallurgica, 1 (1953) 22-31. 
[33] G.K. Williamson, R.E. Smallman, Philosophical Magazine, 1 (1956) 34-46.

[34] C. Garcia-Mateo, F.G. Caballero, C. Capdevila, C. Andres, Scripta Materialia, 61 (2009) 855858.

[35] J. Cornide, G. Miyamoto, F.G. Caballero, T. Furuhara, M.K. Miller, C. García-Mateo, Solid State Phenomena, 172 (2011) 117-122.

[36] F.G. Caballero, M.K. Miller, C. Garcia-Mateo, Metallurgical and Materials Transactions A, 42 (2011) 3660-3668.

[37] J.A. Cameron, J Iron Steel Inst, 194 (1956) 260-267.

[38] C.R. Brooks, Principles of the heat treatment of plain carbon and low alloy seels ASM

International

United States of America, 1996.

[39] H.K.D.H. Bhadeshia, R.W.K. Honeycombe, Steel, microstructure and properties, ButterworthsHeinemann (Elsevier) 2006.

[40] H. Kwon, J.H. Lee, K.B. Lee, C.M. Kim, H.R. Yang, Metallurgical and Materials Transactions A, 28 (1997) 621-627.

[41] H. Bhadeshia, Mathematical Modelling of Weld Phenomena III, eds H. Cerjak and H. K. D. H. Bhadeshia, Institute of Materials, London,, 650 (1997) 229-284.

\section{Figure captions:}

Fig. 1. FEG-SEM pictures of different magnifications obtained after isothermal heat treatment at $200^{\circ} \mathrm{C}$ for $74 \mathrm{~h}(\mathrm{a})$, (c) and (e) and 92h (b), (d) and (f).

Fig. 2. Ferrite plate and austenite film thickness distribution through the microstructure.

Fig. 3. X-ray peack profile of ferrite and austenite with normalized intensities.

Fig. 4. TEM pictures obtained after transformation at $200^{\circ} \mathrm{C}$ for $74 \mathrm{~h} \mathrm{(a)} \mathrm{and} \mathrm{(c)} \mathrm{and} 92 \mathrm{~h}(\mathrm{~b})$ and (d).

Fig. 5. (a) Cementite particles dispersed within the microstructure of sample after 92h and corresponding (b) EDX and (c) SAD pattern. 

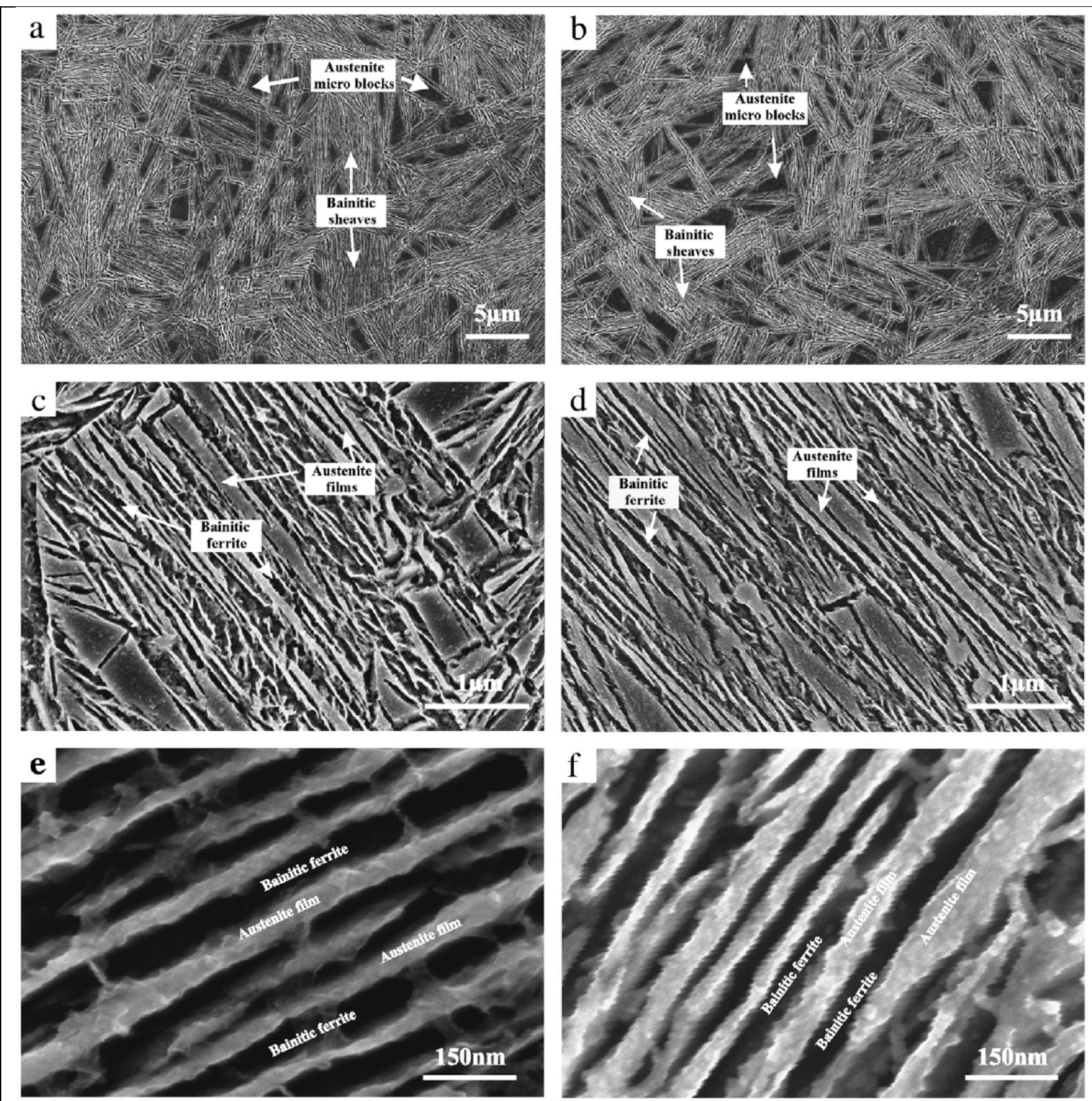

Fig. 1. FEG-SEMpictures of differentmagnifications obtained after isothermal heat treatment at 200

${ }^{\circ} \mathrm{C}$ for $74 \mathrm{~h}(\mathrm{a}),(\mathrm{c})$ and (e) and $92 \mathrm{~h}(\mathrm{~b}),(\mathrm{d})$ and (f). 

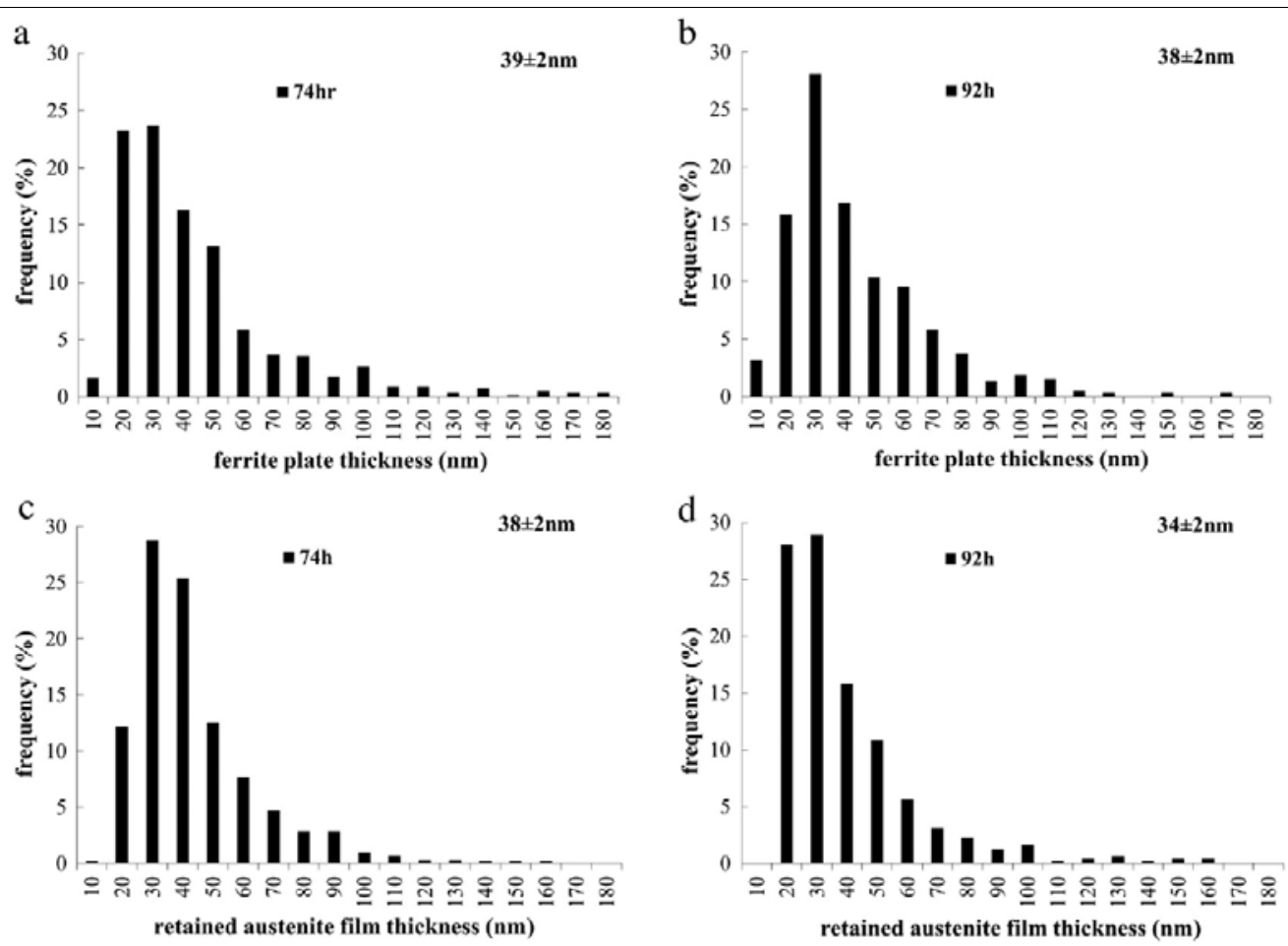

Fig. 2. Ferrite plate and austenite film thickness distribution through the microstructure

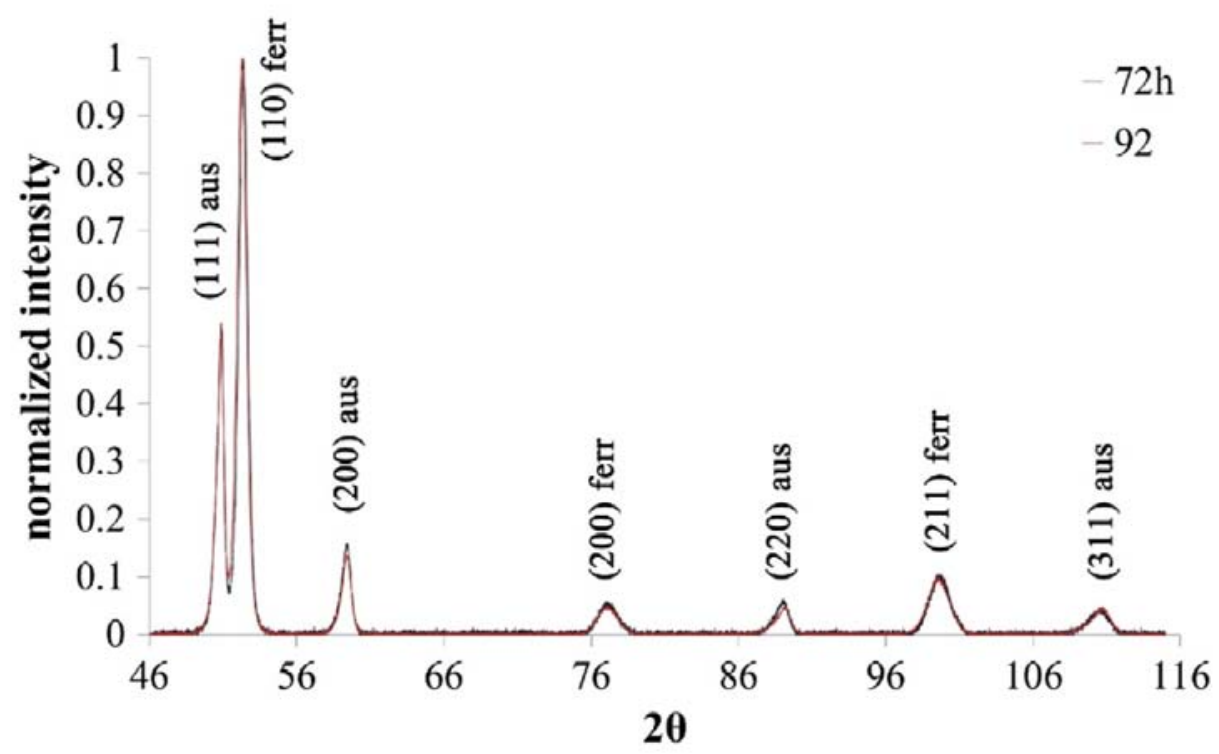

Fig. 3. X-ray peack profile of ferrite and austenite with normalized intensities 

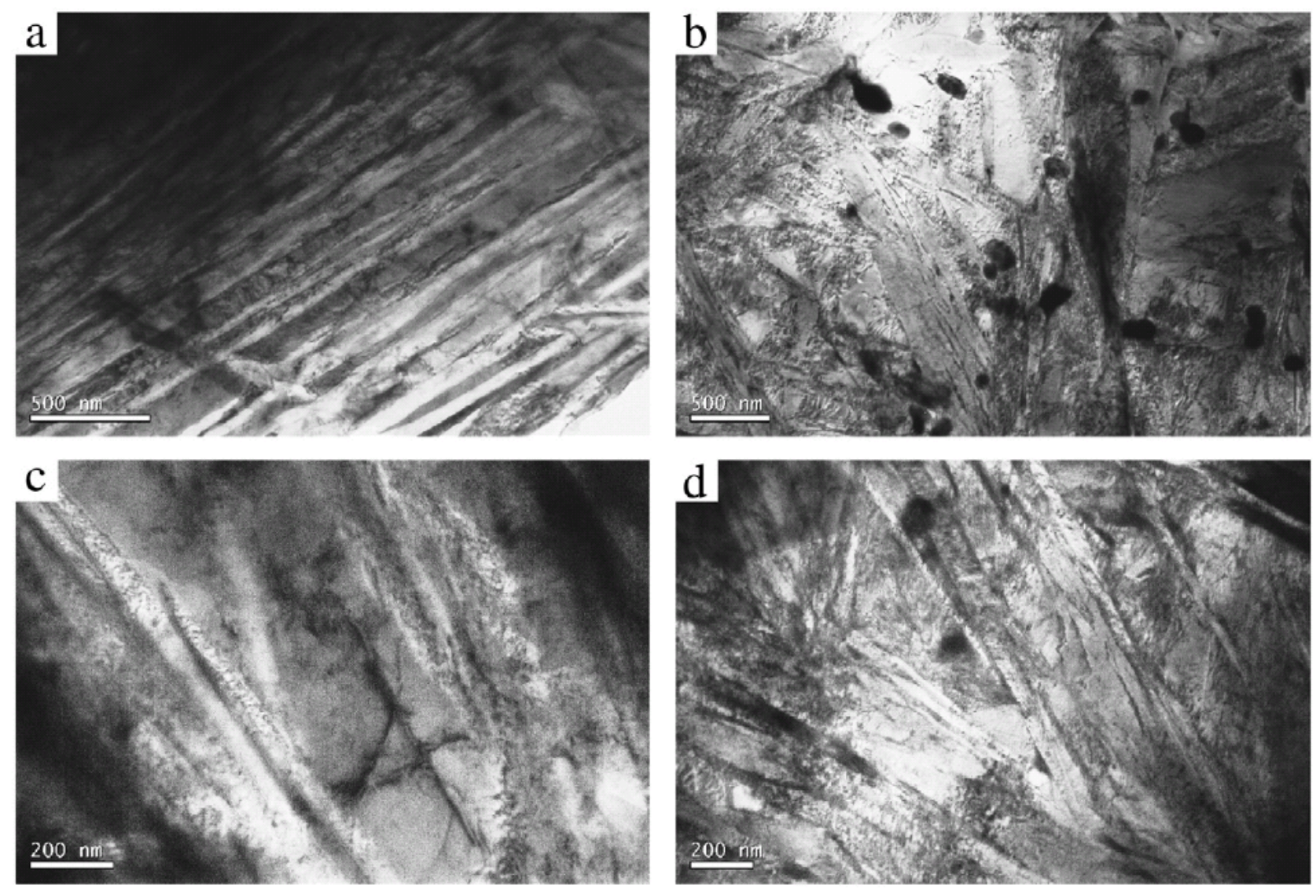

Fig. 4. TEM pictures obtained after transformation at $200^{\circ} \mathrm{C}$ for $74 \mathrm{~h} \mathrm{(a)}$ and (c) and $92 \mathrm{~h}(\mathrm{~b})$ and (d). 



$51 / \mathrm{nm}$

Figure 5. (a) Cementite particles dispersed within the microstructure of sample after $92 \mathrm{~h}$ and corresponding (b) EDX and (c) SAD pattern. 